\title{
Paradigmas psicoeducativos, aportaciones e implicaciones educativas
}

Psychoeducational paradigms, contributions and educational implications

\author{
Hugo A. Buitrón - Ramírez ${ }^{a}$, José F. Hernández-Gracia ${ }^{b}$ Venancio Avendaño - Hernández $^{c}$
}

\begin{abstract}
:
This essay attempts to understand the nature of psychoeducational paradigms, specifically the paradigms focused on the transmission centered on the articulated actions of the student and teacher, through the use of coactive methods, as well as critically assessing their contributions and educational implications.
\end{abstract}

\section{Keywords:}

Psychoeducational paradigms, coercive methods, educational implications

\section{Resumen:}

El presente ensayo, trata de comprender la naturaleza de los paradigmas psicoeducativos, de forma específica los paradigmas enfocados en la transmisión centrada en las acciones articuladas del alumno y profesor, mediante el uso de métodos coactivos, así como valorar críticamente sus aportaciones e implicaciones educativas.

\section{Palabras Clave:}

Paradigmas psicoeducativos, métodos coactivos, implicaciones educativas

\section{Introducción}

\section{Paradigmas enfocados en la transmisión Teoría cognitiva - social}

A partir de los sesenta y hasta nuestros días, se ha desarrollado un considerable número de investigaciones e información teórica sobre las distintas facetas de la cognición (entendida como la adquisición, organización y uso del conocimiento (Neisser, 1982), citado por (Rojas. 1997).

Por otra parte y de acuerdo con Rojas (1997), el paradigma del procesamiento de información se inserta dentro de la gran tradición racionalista en filosofía. Esto es, dar primacía a las representaciones y entidades internas (ideas, conceptos, planes, en fin cualquier tipo de cognición) sobre los hechos externos durante el proceso del conocimiento. Dicho de otra manera, para los cognoscitivistas los comportamientos no son regulados por el medio externo, sino más bien por las representaciones que el sujeto ha elaborado o construido a lo largo de su vida.

De igual forma, Sarabia (2003) señala, que la piedra angular del cognitivismo es el desarrollo de la potencialidad cognitiva del sujeto para que éste se convierta en un aprendiz estratégico que sepa aprender y solucionar problemas donde lo aprendido es adquirido significativamente por éste, de manera que la finalidad de esta teoría se centra en enseñar a pensar o enseñar a aprender, a través del desarrollo de habilidades estratégicas que permitan convertir al sujeto en un

\footnotetext{
a Autor de Correspondencia. Universidad Tecnológica de Tula - Tepeji, Email: hugoarmando.buitron@uttt.edu.mx

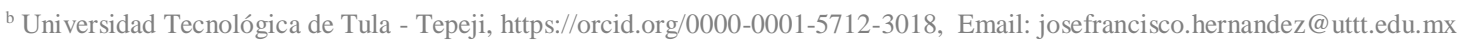


procesador activo, interdependiente y crítico en la construcción del conocimiento.

Puntualizando y con base a lo expuesto por Cobián Sánchez, et al. (1998), se puede decir que el aprendizaje implica que el alumno adopte una disposición para aprender y busque comprometerse a trabajar para conseguirlo, donde el docente tiene como principal función la de preparar la clase y actuar como mediador entre el estudiante y la cultura.

\section{Paradigmas centrados en las acciones articuladas del alumno y profesor, métodos coactivos}

\section{Educación progresiva}

La educación progresiva fue promovida por John Dewey (1967). Con la citada teoría, en los años sesentas, Dewey demostró su oposición a la educación tradicional, criticando el enfoque clásico del conocimiento. Dicho de otra forma, pretendía promover una reconstrucción de las prácticas morales y sociales, así como de las creencias y se concebía como reconstrucción del orden social, en donde sobresalía el papel del educador como guía y orientador de los alumnos.

Por otra parte, Dewey pretendía formular sobre bases nuevas, una propuesta pedagógica en oposición a la escuela tradicional y antigua, ya que pensaba que la nueva educación tenía que superar a la tradición no sólo en los fundamentos del discurso, sino también en la propia práctica. Sin embargo, no existe un método creado por Dewey que en la actualidad pueda ser aplicado, ya que cuando hablaba de su teoría como un método, lo hace a nivel abstracto, en donde señala que no existen métodos "cerrados y envasados".

Por otra parte el citado autor sostiene que:

La historia de la pedagogía se caracteriza por la oposición entre la idea de que la educación es desarrollo desde dentro y la de que es formación desde afuera; la de que está basada en los dotes naturales y la de que la educación es un proceso para vencer las inclinaciones naturales y para sustituirlas por hábitos adquiridos bajo la presión externa. (Dewey, 1967, pp. 11-12)
Precisando y según el autor, la educación tradicional impone modelos, materias y métodos de adultos, para los cuales el alumno requiere de un grado de madurez para su comprensión. Mientras que la educación progresiva, que nace mediante la crítica a la escuela tradicional, trata de cultivar la individualidad y la imposición de la expresión, la adquisición de destrezas, el aprendizaje a través de la experiencia, la máxima utilización de la oportunidades de la vida presente y dejar de lado los fines y materiales estáticos para pasar a un tipo de conocimiento amplio y cambiante.

\section{Educación y trabajo}

A más de un siglo Rabindranath Tagore (1913), funda la escuela Shantiniketan y que en la actualidad es la universidad Vishva Bharathi. En su modelo Tagore afirma, que para que el ser humano se desarrolle a plenitud, es necesario un ambiente sano donde el individuo en su niñez pueda entenderse con otros y a su vez, respetar diferencias de etnia, religión y cultura, en donde el autor basado en su contexto veía estas diferencias tan fuertemente arraigadas en la India y sostenía que estas, separaban al ser humano de sus iguales. En la actualidad, se puede considerar que estos ideales educativos son valiosos, ya que el autor concebía un mundo donde el origen, la pretendida superioridad del color, los distintos credos y culturas no fueran un factor clave en el desarrollo del individuo.

Para finalizar y tomando en cuenta los juicios de los autores consultados, la educación no consiste solamente en el desarrollo intelectual, sino que es preciso fomentar las dotes estéticas y la creatividad del estudiante y en el cual se sostiene que en cuanto más se supere la persona los límites de su naturaleza animal, cuanto más se acerque al humanismo, la libertad y la unidad, más podrá desarrollar su creatividad, en donde solo esta búsqueda daría significado a la vida y la educación sería un esfuerzo por darle a la vida un significado. En este contexto, los objetivos del individuo y los de la comunidad, son casi los mismos.

\section{Referencias}


Cobián Sánchez, María, Anita Nielsen Dhont y Abraham Solís Campos (1998). Contexto sociocultural y aprendizaje significativo. Educar, revista de educación, nueva época, núm. 5, Secretaría de Educación, Gobierno del estado de Jalisco. Recuperado de http://educacion.jalisco.gob.mx/consulta/educar/09/9mariaco.html

Dewey, J. (1967). La educación tradicional frente a la educación progresiva Revista Experiencia y educación. Buenos Aires, Argentina, Editorial Losada.

Hernández, Rojas Gerardo (1997). Módulo Fundamentos del Desarrollo de la Tecnología Educativa (Bases Psicopedagógicas). Coordinador: Frida Díaz Barriga Arceo. México: Editado por ILCE- OEA 1997.

Sarabia, Higuera, Ana M., Ruvalcaba, Aguilera Paola y Santín, Astorga Mirna (2003). El papel del docente. Universidad de Occidente, Campus Mazatlán. Recuperado

http://www.geocities.ws/roxloubet/papel_docente.html 